Relations industrielles

Industrial Relations

\title{
Le sens social à Toronto
}

\section{Ferdinand Vandry}

Volume 5, numéro 5, février 1950

URI : https://id.erudit.org/iderudit/1023324ar

DOI : https://doi.org/10.7202/1023324ar

Aller au sommaire du numéro

Éditeur(s)

Département des relations industrielles de l'Université Laval

ISSN

0034-379X (imprimé)

1703-8138 (numérique)

Découvrir la revue

Citer cet article

Vandry, F. (1950). Le sens social à Toronto. Relations industrielles / Industrial Relations, 5(5), 49-49. https://doi.org/10.7202/1023324ar

Tous droits réservés @ C Département des relations industrielles de l’Université Laval, 1950
Ce document est protégé par la loi sur le droit d'auteur. L'utilisation des services d'Érudit (y compris la reproduction) est assujettie à sa politique d'utilisation que vous pouvez consulter en ligne.

https://apropos.erudit.org/fr/usagers/politique-dutilisation/ 


\section{LE SENS SOCIAL A TORONTO}

\section{Mgr Ferdinand Vandry}

Je dois ajouter que je suis favorablement impressionné par le sens social qui se manifeste à Toronto. Nous savons tous que la vie économique et sociale subit actuellement dans le monde de grandes transformations. On entend parler partout de nouveaux principes et de nouvelles doctrines. Il est malheureux que certains soient portés à croire que l'Eglise catholique combat le capitalisme, prêche la révolution et favorise le communisme. La vérité, c'est que l'Eglise ne fait pas autre chose que d'indiquer, par son enseignement, les moyens d'enrayer la marche du communisme. Elle prêche la justice sociale et la charité, ce qui signifie que les employeurs et les travailleurs doivent chercher à se rapprocher par une meilleure compréhension de leurs problèmes communs. Il faut amener les travailleurs à comprendre que le capital est nécessaire. Si on supprime le capital, l'industrie disparaîtra. Mais les employeurs, de leur côté, doivent admettre que leurs entreprises doivent profiter au bien commun de la société, au lieu de servir exclusivement les intérêts des actionnaires. Il faut assurer le bonheur des travailleurs, car tous, sur terre, ont droit à leur part de bonheur. Faites que tous soient heureux et, par le fait même, vous détruisez le communisme.

\section{LES REVUES EN RELATIONS INDUSTRIELLES}

\section{DROIT SOCIAL}

DROIT SOCIAL est une revue mensuelle d'une quarantaine de pages qui étudie les problèmes de l'organisation professionnelle et du travail, de même que les formes nouvelles de la vie économique, dans leurs rapports avec lordre juridique. Elle attire l'attention de ses lecteurs sur les éléments de ce monde en formation qui taille son domaine aux frontières du droit privé et du droit public.

Cette publication contient habituellement une couple d'articles élaborés préparés soit par des professeurs de droit choisis dans les principales universités françaises, soit par des officiers ou des fonctionnaires du gouvernement occupant des postes de commande. Ces travaux sont de nature à intéresser, non seulement les spécialistes en législation sociale, mais encore tous ceux qui suivent de près l'évolution sociale et juridique contemporaine.

Il va sans dire que la plupart des études publiées dans DROIT SOCIAL portent sur des problèmes français, mais on en trouve aussi qui traitent de certains points de la situation sociale et juridique dans d'autres pays.

DROIT SOCIAL est divisé en deux parties: organisation professionnelle et travail. C'est dans la première que l'on trouve, le plus souvent, les travaux les plus poussés. Elle se termine toujours par une chronique sur la situation économique, laquelle consiste en une synthèse
Si l'on veut assurer la prospérité et le bonheur de ce pays, il faut amener les capitalistes à comprendre leur devoir, les convaincre qu'il ne suffit pas que leur argent leur profite à eux-mêmes et à leurs actionnaires, mais qu'il doit aussi profiter aux ouvriers. La Compagnie Robert Simpson fait preuve, en ce sens, d'un sens social exemplaire. Si tous les employeurs du Canada étaient animés du même esprit que $M$. Charles Burton, le Président de la Compagnie Simpson, on n'aurait pas à craindre le danger communiste en ce pays.

J'ai l'impression que les principaux employeurs de Toronto prennent de plus en plus conscience de leurs responsabilités sociales. Ils s'intéressent beaucoup aux diverses organisations sociales et charitables, telle la Croix-Rouge, laquelle est une institution particulièrement méritante. Ils se préoccupent aussi du bien-être de leurs employés. Toronto ouvre ainsi la voie à la justice sociale et à la prospérité nationale.

Telles sont quelques-unes des raisons qui m'amènent à rendre hommage à la Ville de Toronto.

Extrait d'une allocution prononcée lors d'une réunion du Club anglo-français de Simpson's, le 24 novembre 1949.

de l'état de l'économie au moment de la parution de la revue: activité industrielle et agricole, niveau des prix et de la monnaie. etc. Cette chronique est rédigée par Alfred Sauvy, directeur de l'Institut national d'études démographiques et membre du Conseil économique.

La deuxième partie contient plusieurs rubriques: $\& \mathrm{Ju}$ risprudence récente en matière sociale », «Bibliographie \$, « Chronologie sociale française », et « La situation sociale ». Il y a aussi, quelquefois, une chronique législative, des annexes et des documents. Dans cette partie, on trouve le texte de certains arrêts du Conseil d'Etat et d'abondantes citations de décisions judiciaires, dont quelquesuns sont commentés par un collaborateur régulier de la revue. Les trois derniers numéros de DROIT SOCIAL, soit ceux de juin, de juillet-août et de septembre-octobre, présentent une bibliographie méthodique sur la réforme de l'entreprise. Cet essai bibliographique porte uniquement sur la participation du personnel aux résultats de l'activité de l'entreprise, et se limite aux ouvrages et brochures parus depuis 1944.

Depuis octobre 1949, DROIT SOCIAL publie un supplément intitulé «SECURITE SOCIALE ET PRESTATIONS FAMILIALES ». Elle a pour but d'étudier séparément, mais toujours dans l'esprit de DROIT SOCIAL, l'ensemble des problèmes que pose la politique moderne de sécurité sociale sous leur double aspect d'indemnisation et de prévention des risques sociaux: maladie, vieillesse, accidents du travail, maladies professionnelles, 